\title{
Influence of different components on resistance of ships movement in ice
}

\author{
Zuev Valeriy Andreevich \\ Department «Shipbuilding and aircraft engineering» \\ Nizhny Novgorod State Technical University \\ Nizhny Novgorod, Russia \\ ship@nntu.ru
}

\author{
Gramuzov Evgeniy Mikhailovich \\ Department «Shipbuilding and aircraft engineering» \\ Nizhny Novgorod State Technical University \\ Nizhny Novgorod, Russia \\ terkor@nntu.ru
}

\author{
Kalinina Nadezhda Viktorovna \\ Department «Shipbuilding and aircraft engineering» \\ Nizhny Novgorod State Technical University \\ Nizhny Novgorod, Russia \\ nvk5133@mail.ru
}

\begin{abstract}
The process of icebreaker interaction with the ice cover is described, the method of calculation of resistance during the motion of ships by continuous motion in smooth continuous ice is given. The semi-empirical method of calculating the ice resistance is divided into components and includes not only the main dimensions of the ships, but also the shape of the hull, the physical and mechanical characteristics of ice and snow. The separation of resistance into components was studied using the example of the icebreaker «Nevskaya Zastava», depending on the speed of movement and the thickness of the ice cover.
\end{abstract}

Keywords - solid ice, continuous movement, ice resistance

\section{INTRODUCTION}

Despite some changes in climatic factors over the last years, ice conditions during winter navigation have not become milder. Difficult situations in certain areas often arise due to the shortage of icebreakers to ensure the posting of ships. An analysis of the current situation indicates the need for the design and construction of new icebreakers.

Most of the ports of Russia freeze in the winter, which greatly complicates the movement of ships and negatively affects the volume of cargo turnover in ports. For year-round operation of ports on freezing water areas, it is necessary to have icebreakers for ships wiring in ice. Icebreaking fleet is by far the most effective and actual means, which provides ships access to freezing ports. Therefore, studies of ice navigation issues are relevant $[1,5]$.

\section{THE PROCESS OF ICEBREAKER INTERACTION WITH THE ICE COVER}

The main mode of icebreaker movement in ice, the thickness of which is less than the limit, is continuous movement with a constant (steady-state motion) or variable speed (acceleration, deceleration).
In the process of moving in continuous ice, the icebreaker destroys the ice cover. This destruction occurs due to the efforts of the icebreaker enclosed in the hull at the point of contact with the edge of the ice cover. Interaction (contact) with the ice edge can occur in different places along the length of the bow near the waterline.

The main principle of breaking ice is the destruction of the ice plate due to its bending. This is facilitated by the icebreaker outline of the hull, capable of creating significant vertical components of forces at the point of contact with ice.

When meeting with the ice field, the icebreaker "crawls" with the bow to the ice edge and breaks it with a vertical force (gravity force). Continuing the movement, the icebreaker overcomes the resistance of the hacked ice in the formed channel, expands it, breaks, spreads and heats the ice with boards. Then the cycle of movements is repeated. Practically, cyclicity is poorly expressed, and the icebreaker's movement can be regarded as continuous [6].

Let us consider the process of destruction of ice by the stem and sides of the icebreaker's hull.

When the icebreaker advances forward, the stem periodically comes into contact with the ice cover and destroys it. This happens as follows. The introduction of the stem into the ice cover is accompanied by an increase of the contact force due to the reaction of the ice plate lying on the hydraulic elastic foundation to its deflection. At the same time, two processes occur simultaneously: an increase in bending stresses in the ice plate and local destruction of the ice edge at the point of contact.

Flexural stresses increase and at some point reach the limit of ice strength for bending. The maximum of these stresses is located in the immediate vicinity of the stem, resulting in the appearance of the first radial crack in the ice, which goes ahead of the vessel. After the appearance of this crack, a redistribution of stresses occurs in the ice plate. With further 
loading, one or more radial cracks arise from each side that extend from the stem to the periphery. After the appearance of a series of radial cracks, the zone of maximum stress is removed from the stem, and further bending of the ice plate leads to the appearance of the first concentric crack, which shape is close to the circle with the center at the point of contact and some radius.

The formation of the first concentric crack does not lead to a loss of the bearing capacity of the ice cover. Firstly, this is due to the fact that large-sized ice plates (with further loading) continue to bend, and secondly, with the formation of significant contact stresses in the compressed zone of the crack that prevent the break of ice. This contributes to the emergence of subsequent concentric cracks, which are formed sequentially from the periphery to the place of application of the load. Bending of ice occurs until the ice breaks along the nearest concentric fracture with radius $r \cong(3 \ldots .5) h$. The stem contact with the continuous ice cover ends with a complete break.

In the process of loading the ice with a stem, up to the break itself, local destruction of the ice edge takes place at the point of contact, caused by the need to perceive significant contact forces. To perceive these forces in the process of loading the ice, there should be an increase in the area of contact due to crushing and sometimes cutting, the edge of the ice. Local fracture of the edge depends significantly on the thickness and strength of the ice cover, as well as on the sharpness of the hull contours in the stem region. For large ice thicknesses and, consequently, large contact forces typical of sea icebreakers, the depth of destruction of the edge can reach $1,0 \ldots 1,5$ meters. For river icebreakers, operating in ice of lesser thickness and greater strength, local fracture processes are less developed.

After breaking the ice cover with the stem and advancing the icebreaker forward, inclined sections of the side come into contact with the ice. The interaction of the hull with ice here is analogous to the destruction of the stem by only the difference that the configuration of the plate at the contact point is different, and the surface of the hull in the interaction zone is plane. Icebreaker sides break ice segments from the ice plate. In places where the hull contacts the ice, there is a local crushing and crushing of the edge of the ice cover. The breaking out of the ice segments by the sides can occur both along the lines of cracks formed by the stem, and along new cracks formed as a result of the ice bending of the icebreaker's sides.

The fragments of the destroyed ice cover rotate and move apart, following the contours of the underwater part of the icebreaker's hull. The movement trajectory of ice floes depends on the shape of the hull [4]. During the work of river icebreakers with large ratios $B / T$, gentle buttocks and a large collapse of the frames, almost the entire broken ice falls under the icebreaker's body, forming an ice "shirt" in its underwater part [3]. The ice cover of the underwater part of the hull is located at a considerable distance from the stem along the length of the icebreaker and down from the operating waterline. The width of the cladding contact with ice fragments along the perimeter of the frame from each side is approximately equal to the half-width of the ice waterline in the corresponding area along the length of the ship. Between the zones of ice hanging on the right and left sides, a gap in the ice shirt is formed.

Fragments of ice in the bow of the ship form a shell, which tightly adjacent to the outer plating. Ice in this area of the hull is pressed against the shell by the forces of ice buoyancy and hydrodynamic forces, since the outer normal to the outer skin is an acute angle with the direction of motion.

The density of the shell in the ship stern decreases due to the opposite effect of the hydrodynamic forces. When the ice shell approaches the stern, it breaks away.

The stability of the ice cover in the stern of the ship depends on the shape of the underwater hull and the speed of the icebreaker. Part of the ice floats on the sides after passing a wide part of the hull of the ship, and some of the ice remains under the bottom and gets into the screws. Ice, falling into the screws, is additionally crushed, changing its draft. After passing the vessel, almost entire ice emerges in the channel, forming a continuity of 9-10 points.

Observations of the movement of icebreakers in continuous ice show that, despite the frequency of efforts related with breaking ice, continuous movement in the solid ice occurs with a practically constant ascent and a differentiation to the stern, the magnitude of which depends on the thickness of ice and speed. This is due not to the simultaneity of contact in various parts of the hull and the inertia of the icebreaker, which has a large mass. The speed of continuous motion is also practically constant. Therefore, one can assume that the continuous course of the icebreaker in solid ice field has the character of steady motion.

Practice shows that solid homogeneous snowless ice is rarely found in real conditions. Therefore, it is necessary to take into account the presence of snow cover [6].

\section{MATHEMATICAL MODEL OF CALCULATING THE ICE RESISTANCE}

The semi-empirical method of calculating the ice resistance was developed on the basis of the described physico-mechanical picture of the destruction of ice cover by ships and theoretical and experimental studies at the Nizhny Novgorod State Technical University [2].

Pure ice resistance of solid ice and snow resistance can be represented in the form of components in a compact and convenient for use form:

$$
R=R_{d v}+R_{d s t}+R_{f v}+R_{f s t}+R_{s n}
$$

where $R_{d v}, R_{d s t}$ - speed -dependent and static components of destruction of the pure ice resistance; $R_{f v}, R_{f s t}$ - speeddependent and static components of ice fragments of pure ice resistance; $R_{s n}$ - snow resistance; 


$$
\begin{aligned}
& R_{d v}=k_{d v} \operatorname{Fr}_{h} \operatorname{tg} \varphi_{1 f}\left(\frac{R_{d s t}}{k_{d s t}}\right) \\
& R_{d s t}=k_{d s t} \frac{h^{4}}{\alpha d}\left[\left(1+f \gamma_{l f f}\right)+k_{s f} \gamma_{s f} \frac{d \alpha^{2}}{h} \sqrt{\frac{\operatorname{tg} \varphi_{2 f}}{1+\operatorname{tg}^{2} \varphi_{2 f}}}+\right. \\
& \left.+0,66\left(1+f \Phi_{l t}\right) B \alpha+\frac{k_{s b} \Phi_{s} d \alpha^{3} B}{h}\right] ; \\
& R_{f v}=k_{f v} \rho_{\text {ice }} h B v^{2}\left[\left(1+\frac{0,19}{\left(0,215+\operatorname{Fr}_{h} \operatorname{tg} \varphi_{1 f}\right)} \frac{\rho}{\rho_{\text {ice }}} \frac{1}{\alpha h}\right) \times\right. \\
& \left.\times\left(\Phi_{i}+f \Phi_{i t}\right)+\frac{2 \rho}{\rho_{\text {ice }}} \frac{\Omega_{\text {ice }}}{B h}\left(\Phi_{g}+f \Phi_{g t}\right)\right] ; \\
& R_{f s t}=k_{f s t}\left(\rho-\rho_{\text {ice }}\right) g h \Omega_{\text {ice }}\left(\Phi_{p}+f \Phi_{p t}\right) \text {; } \\
& R_{s n}=k_{s n}\left(\rho-\rho_{s n}\right) g h_{s n} \Omega_{\text {ice }}\left(\Phi_{p}+f \Phi_{p t}\right) ;
\end{aligned}
$$

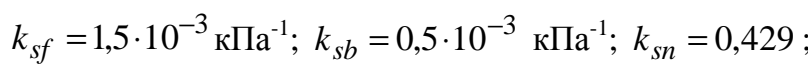

$$
\begin{aligned}
& k_{d s t}=1,3 \cdot 10^{6} \mathrm{\kappa \Pi а}^{2} ; k_{d v}=4,7 \cdot 10^{6} \mathrm{\kappa \Pi а}^{2} ; k_{f s t}=2,7 ; \\
& k_{f v}=0,88 \text {; } \\
& \gamma_{l f f}=\sqrt{\frac{1}{n_{x f}^{2}}+\frac{1}{n_{z f}^{2}}} ; \gamma_{s f}=\sqrt{\frac{1}{n_{z f}^{2}}-1} ; \\
& \Phi_{l t}=\frac{2}{B} \int_{0}^{B / 2} \sqrt{\frac{1}{n_{x}^{2}}+\frac{1}{n_{z}^{2}}} \mathrm{~d} y ; \quad \Phi_{s}=\frac{2}{B} \int_{0}^{B / 2} \sqrt{\frac{1}{n_{z}^{2}}-1} \mathrm{~d} y ; \\
& \Phi_{p}=\frac{1}{\Omega_{\text {ice }}} \int_{\Omega_{\text {ce }}} n_{x} n_{z} \mathrm{~d} \Omega ; \Phi_{p t}=\frac{1}{\Omega_{\text {ice }}} \int_{\Omega_{\text {ce }}} n_{z} \sqrt{1-n_{x}^{2}} \mathrm{~d} \Omega ; \\
& \Phi_{g}=\frac{1}{\Omega_{\text {ice }} \Omega_{\text {ice }}} n_{x}^{3} \mathrm{~d} \Omega ; \quad \Phi_{g t}=\frac{1}{\Omega_{\text {ice }}} \int_{\Omega_{\mathrm{ice}}} n_{x}^{2} \sqrt{1-n_{x}^{2}} \mathrm{~d} \Omega \\
& \Phi_{i}=\frac{2}{B} \int_{0}^{B / 2} \sqrt{n_{x}^{2}} \mathrm{~d} y ; \quad \Phi_{i t}=\frac{2}{B} \int_{0}^{B / 2} n_{x} \sqrt{1-n_{x}^{2}} \mathrm{~d} y ; \\
& n_{x}=\frac{\operatorname{tg} \varphi_{2}}{\sqrt{1+\operatorname{tg}^{2} \varphi_{2}+\operatorname{tg}^{2} \varphi_{3}}} ; n_{z}=\frac{\operatorname{tg} \varphi_{3}}{\sqrt{1+\operatorname{tg}^{2} \varphi_{2}+\operatorname{tg}^{2} \varphi_{3}}} ; \\
& \alpha=\sqrt[4]{\rho g / d} ; d=\frac{E h^{3}}{12\left(1-\mu^{2}\right)} ;
\end{aligned}
$$

$B$-width of the icebreaker, $\mathrm{m} ; f$ - coefficient of friction of ice on the ship's hull; $h$ - thickness of the ice, $\mathrm{m} ; h_{\mathrm{sn}}-$ thickness of snow, $\mathrm{m} ; g$ - acceleration of gravity, $\mathrm{m} / \mathrm{s}^{2} ; \mathrm{Fr}_{h}=\frac{v}{\sqrt{g h}}-$

Froude number in the thickness of ice; $v-$ speed, $\mathrm{m} / \mathrm{s} ; \boldsymbol{\Omega}_{\text {ice }}$ the area of the underwater part of the hull, surrounded by ice, $\mathrm{m}^{2} ; n_{x}, n_{z}$ - direction cosines of the outer normal to the ship's skin with longitudinal $O x$ and vertical $O z$ axes; $\varphi_{1}, \varphi_{2}, \varphi_{3}$ angles of inclination of the buttock to the horizon, the waterline to the diametric plane, and the frame to the vertical at some point of the ship's surface; $\varphi_{1 f}, \varphi_{2 f}, \varphi_{3 f,} n_{x f}, n_{z f}$ - angles and direction cosines on the stem in the region of the active waterline; $\alpha$ - bending parameter of the plate on the elastic base; $d$ - cylindrical rigidity of the ice plate; $E$ - modulus of elasticity, $\mathrm{kPa} ; \mu$ - the Poisson's ratio of ice; $\rho, \rho_{\mathrm{ice}}, \rho_{\mathrm{sn}}-$ density of water, ice and snow, $\mathrm{t} / \mathrm{m}^{3} ; k_{d s t}, k_{d v}, k_{f s t}, k_{f v}$ - empirical coefficients compensating for the inaccuracies of the theoretical resistance model, which are determined taking into account full-scale data on the ice breakability of icebreakers in solid ice [2].

Resistance (1) takes into account not only the main dimensions of ships, but also the shape of the hull, the physical and mechanical characteristics of ice and snow.

The shape of the hull is taken into account by introducing in the calculation models the integral functions of the geometry $\gamma_{1 t f}, \gamma_{s f}, \Phi_{i}$, which are obtained from the spatial consideration of the hull interaction with ice [2].

\section{MAthematicAl MOdEL OF CALCULATING THE ICE RESISTANCE}

When investigating the resistance to the movement of ships in solid ice, it is interesting to know what the proportion of each component is. The «Nevsky Zastava» ice-breaker of project 2805, built by Shipbuilding Company Almaz, St. Petersburg, for work in the water area of St. Petersburg, was selected to assess the various components of the ice resistance.

The vessel has the class of the Russian River Register: "MSP 3,5 (icebreaker) A". The main characteristics of the icebreaker are given in Table I.

To take into account the shapes of the hull of the icebreaker in (1), the functions of geometry were calculated [2] and are given in Table II.

TABLE I. THE MAIN CHARACTERISTICS OF ICEBREAKER, PROJECT 2805

\begin{tabular}{|l|l|c|}
\hline 1. & $\begin{array}{l}\text { Class of the icebreaker according to } \\
\text { the Russian River Register }\end{array}$ & $\begin{array}{c}\text { M-SP 3,5 (icebreaker) } \\
\text { A }\end{array}$ \\
\hline 2. & Length $L_{W L}, \mathrm{~m}$ & 38,0 \\
\hline 3. & Width $B, \mathrm{~m}$ & 11,8 \\
\hline 4. & Board height $H, \mathrm{~m}$ & 5,2 \\
\hline 5. & Maximum draft $T, \mathrm{~m}$ & 3,8 \\
\hline 6. & Minimum draft, $\mathrm{m}$ & 3,39 \\
\hline 7. & Displacement $D, \mathrm{t}$ & 912 \\
\hline 8. & Coefficient of total completeness $\delta$ & 0,535 \\
\hline 9. & Main engine power $N, \mathrm{~kW}$ & $2 \times 1800$ \\
\hline 10. & Speed on clean water $v_{0}, \mathrm{~km} / \mathrm{h} / \mathrm{m} / \mathrm{s}$ & $20 / 5$ \\
\hline 11. & Mooring thrust, $\mathrm{kN}$ & 380 \\
\hline 12. & Autonomy, day & 5 \\
\hline
\end{tabular}


The physical and mechanical characteristics of ice, snow and water are taken as average for river conditions: water density $\rho=1 \mathrm{t} / \mathrm{m}^{3}$; the ice density is $\rho_{\text {ice }}=0,9 \mathrm{t} / \mathrm{m}^{3}$; snow density $\rho_{s n}=0,3 \mathrm{t} / \mathrm{m}^{3}$; Poisson's ratio $\mu=0,33$; modulus of elasticity $E=$ $5 \cdot 10^{6} \mathrm{kPa}$; coefficient of friction of ice on the outer skin $f=$ 0,15 .

TABLE II.GEOMETRY FUNCTIONS OF ICEBREAKER, PROJECT 2805

\begin{tabular}{|c|c|c|c|c|c|}
\hline Functions & Values & Functions & Values & Functions & Values \\
\hline $\operatorname{tg}\left(\varphi_{1}\right)$ & 0,462 & $\Phi_{s}$ & 1,323 & $\Phi_{g}$ & 0,032 \\
\hline $\operatorname{tg}\left(\varphi_{2}\right)$ & 1,247 & $\Phi_{p}$ & 0,119 & $\Phi_{g t}$ & 0,073 \\
\hline$\gamma_{l t f}$ & 2,771 & $\Phi_{p t}$ & 0,590 & $\Omega_{\text {ice }}, \mathrm{M}^{2}$ & 205,7 \\
\hline$\gamma_{s f}$ & 0,592 & $\Phi_{i}$ & 0,147 & $S_{W L}, \mathrm{M}^{2}$ & 180,5 \\
\hline$\Phi_{l t}$ & 3,769 & $\Phi_{i t}$ & 0,336 & & \\
\hline
\end{tabular}

\section{ANALYSIS OF THE ICE RESISTANCE COMPONENTS}

In the course of the research, it was revealed that the icebreaker would overcome the solid ice by continuous movement and by ramming [3]. The dependencies of the pure ice resistance in the solid snowless ice of various thicknesses and thrust on the hook on the speed of movement are calculated and are shown in Fig. 1.

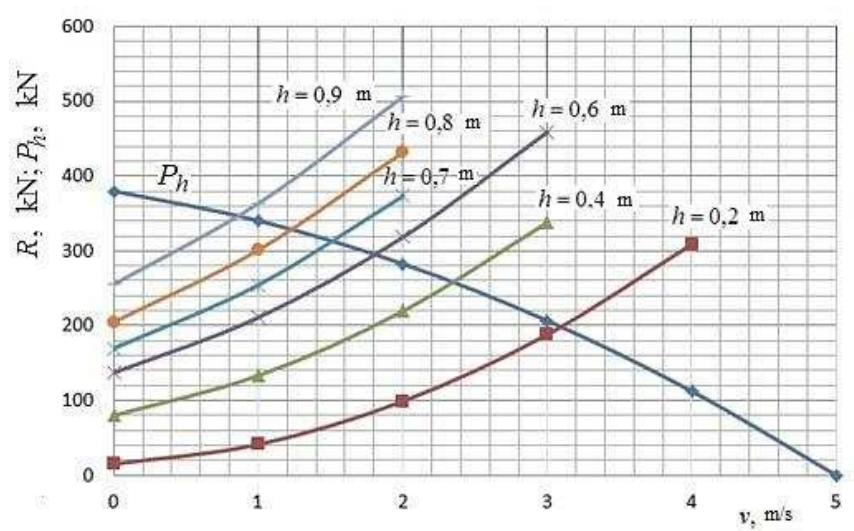

Fig. 1. Dependencies of the pure ice resistance in the solid snowless ice of various thicknesses for the project 2805 icebreaker

The thrust on the hook of the icebreaker is approximated by expression [2]:

$$
P_{h}=P_{m}\left[1-0,4\left(\frac{v}{v_{0}}\right)-0,6\left(\frac{v}{v_{0}}\right)^{2}\right],
$$

where $P_{m}$ - thrust on mooring lines, $\mathrm{kN} ; v$ - speed of the icebreaker at the current time, $\mathrm{m} / \mathrm{s} ; \boldsymbol{v}_{0}$ - speed of movement on clean water at a given power, $\mathrm{m} / \mathrm{s}$. The achievable speed of the ship $v$ is determined from the joint solution of the equations $P_{h}=R$, where $P_{h}=P e-R_{w}$ - thrust on the hook (called by analogy with tugs), is defined as the difference between the useful thrust of propellers $P e$ and the resistance of water $R_{w}$ at a given speed of movement.

The curves of the ice breakability of the icebreaker during continuous movement in solid ice, depending on the thickness of the snow cover on ice, are shown in Fig. 2.

The presence of a snow cover on the ice increases the resistance to the movement of ships, reduces the speed of movement, worsens the ice fluidity.

The resistance of snow does not depend on the thickness of the ice and the speed of movement. Every $10 \mathrm{~cm}$ of snow is added with a resistance of $12.5 \mathrm{kN}$.

This is due to the fact that the icebreaker's body does not slip so well over the snow as it does on ice, and that much force is wasted on compacting snow. However, until now the mechanical properties of snow have not been studied in sufficient detail, and their diversity and seasonal variation of characteristics do not allow us to sufficiently fully take into account the role of snow in the calculation of ice resistance.

All characteristics of snow depend on its density, but the density of snow varies from 0,1 to $0,7 \mathrm{t} / \mathrm{m}^{3}$. The density of snow on ice depends on the «history» of its formation, including all meteorological factors, temperature, water availability, etc. The snow density is $0,1 \mathrm{t} / \mathrm{m}^{3}$ for loose freshly fallen snow and $0,30 \mathrm{t} / \mathrm{m}^{3}$ for compacted for its own weight, the pressure of newly formed layers and the effect of wind.

The effect of snow density on the ice resistance of the vessel is shown in Fig. 3, depending on the thickness of the snow cover. Fig. 3 shows that snow density influences its resistance. The component of resistance of freshly fallen snow $\left(\rho_{\mathrm{sn}}=0,1 \mathrm{t} / \mathrm{m}^{3}\right)$ is increased by $29 \%$ in comparison with the component of the compacted snow cover $\left(\rho_{\mathrm{sn}}=0,3 \mathrm{t} / \mathrm{m}^{3}\right)$ at any thickness of snow.

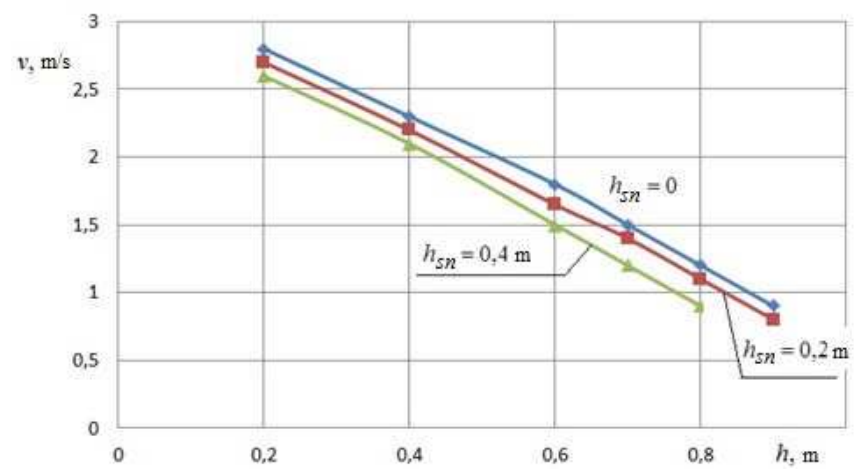

Fig. 2. Curves of ice breakability at different snow thickness for project 2805 icebreaker

The calculation and experimental separation of the resistance of the icebreaker into components is shown in Fig. 4...11 depending on the speed of movement and the thickness of the ice. 
All the components of the resistance, other than the resistance of snow, depend on the thickness of the ice $h$ and their growth, depending on $h$, is different.

The static components of resistance $R_{d s t}, R_{f s t}$ for small ice thicknesses are almost identical. $R_{f_{s t}}$ with increasing thickness of the ice grows less intensively than $R_{d s t}$ (Fig. 6). Every $10 \mathrm{~cm}$ of ice increases $R_{f s t}$ to $9 \mathrm{kN}$ (Fig. 5). The static component of destruction $R_{d s t}$ increases faster with increasing thickness of ice (Fig. 4).

The components of the resistance $R_{d v}, R_{f v}$, depending on the speed of movement, vary in different ways depending on the ice conditions (Fig. 7, 8). The velocity component of destruction $R_{d v}$ when moving with high velocities increases more intensively with increasing ice thickness (Fig. 7). The velocity component of ice fragments $R_{f v}$ depends on the square of the velocity and is almost independent of the ice thickness (Fig. 8).

Fig. 9-11 and table III show the resistance of icebreaker project 2805 when it is divided into components for specific ice conditions: ice thickness of $0,2 \mathrm{~m}, 0,4 \mathrm{~m}$ and $0,6 \mathrm{~m}$ with $0,2 \mathrm{~m}$ snow.

TABLE III.SEPARATION OF ICE RESISTANCE OF PROJECT 2805 ICEBREAKER ON COMPONENTS

\begin{tabular}{|c|c|c|c|c|c|c|c|}
\hline $\begin{array}{c}\text { Ice } \\
\text { conditions }\end{array}$ & $\begin{array}{c}\text { Dimen- } \\
\text { sion }\end{array}$ & $R_{s n}$ & $R_{d s t}$ & $R_{f s t}$ & $R_{d v}$ & $R_{f v}$ & $R$ \\
\hline $\begin{array}{c}h=0,2 \mathrm{~m}, \\
h_{s n}=0,2 \mathrm{~m}\end{array}$ & $\mathrm{kN}$ & 25 & 83 & 54 & 98 & 43 & 303 \\
\cline { 2 - 8 } & $\%$ & 8,3 & 27,4 & 17,8 & 32,3 & 14,2 & 100,0 \\
\hline $\begin{array}{c}h=0,4 \mathrm{~m}, \\
h_{s n}=0,2 \mathrm{~m}\end{array}$ & $\mathrm{kN}$ & 25 & 44 & 36 & 82 & 83 & 270 \\
\cline { 2 - 8 } & $\%$ & 9,3 & 16,3 & 13,3 & 30,4 & 30,7 & 100,0 \\
\hline $\begin{array}{c}h=0,6 \mathrm{~m}, \\
h_{s n}=0,2 \mathrm{~m}\end{array}$ & $\mathrm{kN}$ & 25 & 16 & 18 & 50 & 121 & 230 \\
\cline { 2 - 8 } & $\%$ & 10,9 & 7,0 & 7,8 & 21,7 & 52,6 & 100,0 \\
\hline
\end{tabular}

\section{CONCLUSION}

Analyzing these dependencies, one can draw the following conclusions

The proportions of the components in the ice resistance of the ship are different and depend on the speed of movement and ice conditions. The resistance of snow $R_{s n}$ does not depend, and the velocity component of ice fragments $R_{f v}$ is almost independent of the thickness of ice. If the thickness of ice is less, the proportion of component $R_{f v}$ in the resistance is greater. This is due to the movement with higher velocities in thin ice.

With increasing thickness of the ice cover, the proportion of other components $R_{d v}, R_{f s t}, R_{d s t}$ decreases, but not so much, as the proportion of component $R_{f v}$ increases at the calculated velocities of the steady motion.

Analysis of the components of the ice resistance confirms the main causes of ice resistance.

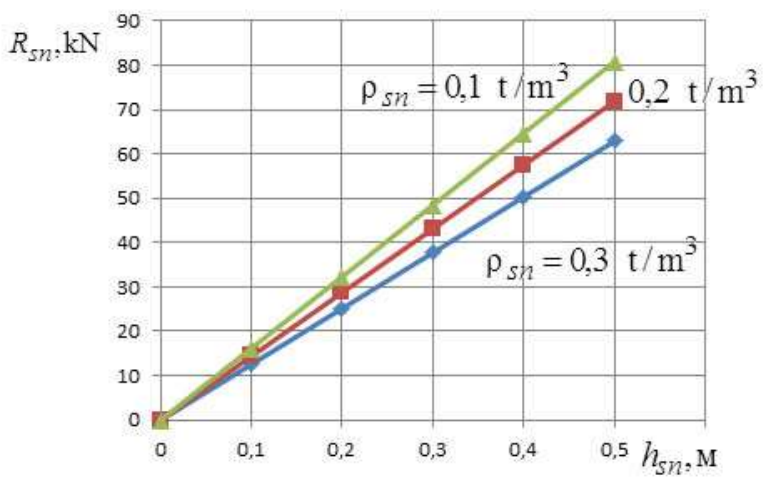

Fig. 3. Component of snow resistance of different thickness and density for project 2805 icebreaker

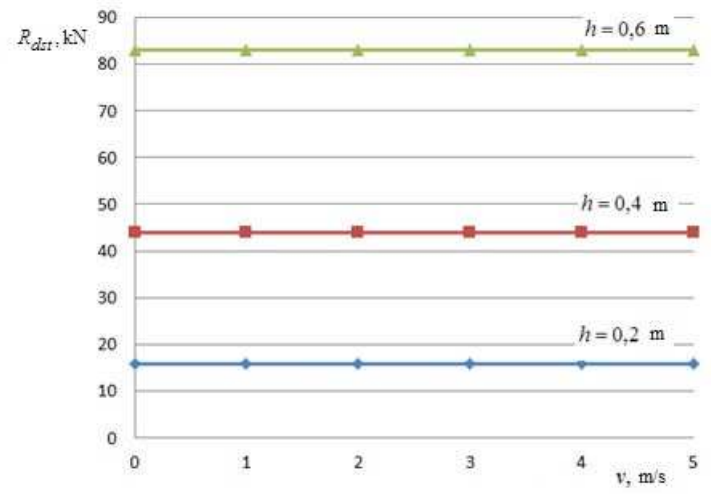

Fig. 4. Static component of destruction of pure ice resistance for project 2805 icebreaker

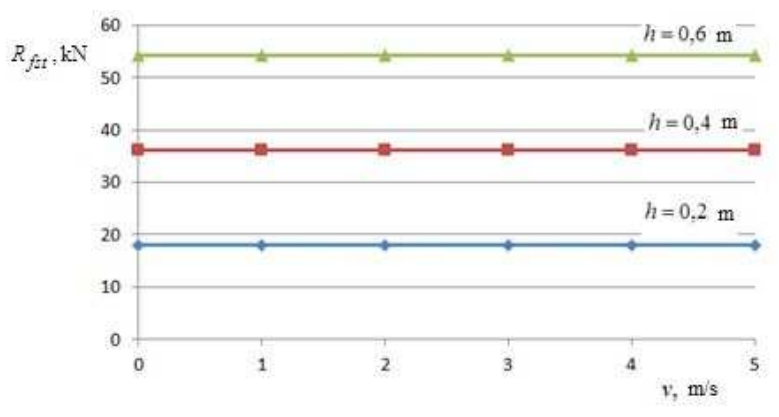

Fig. 5. Static component of ice fragments of pure ice resistance for project 2805 icebreaker 


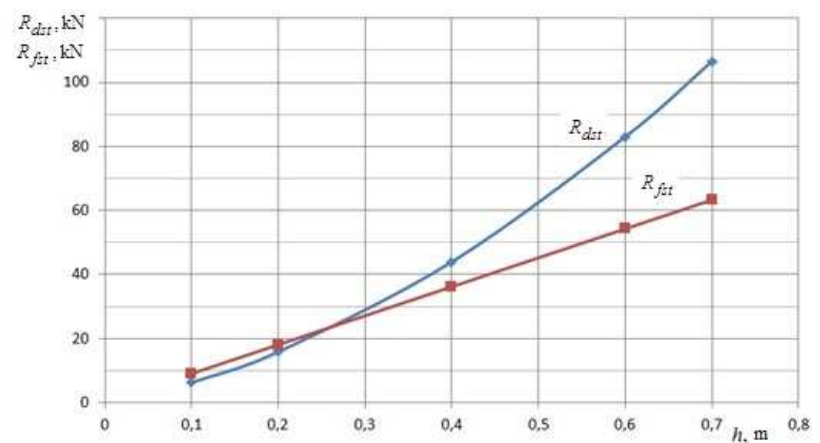

Fig. 6. Static components of destruction and of ice fragments of pure ice resistance for project 2805 icebreaker

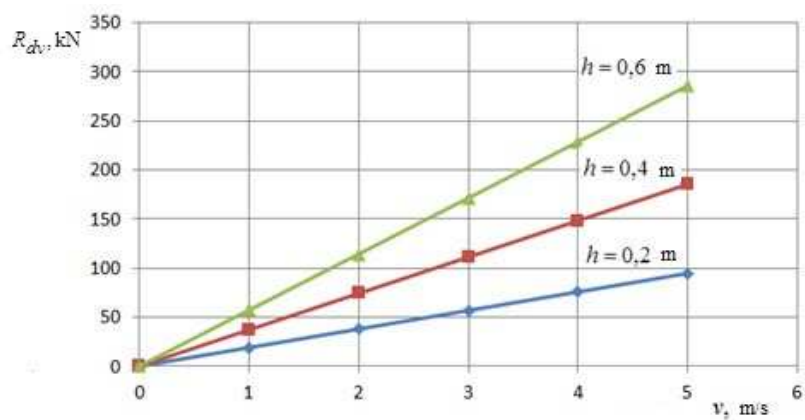

Fig. 7. Speed-dependent component of destruction of pure ice resistance for project 2805 icebreaker

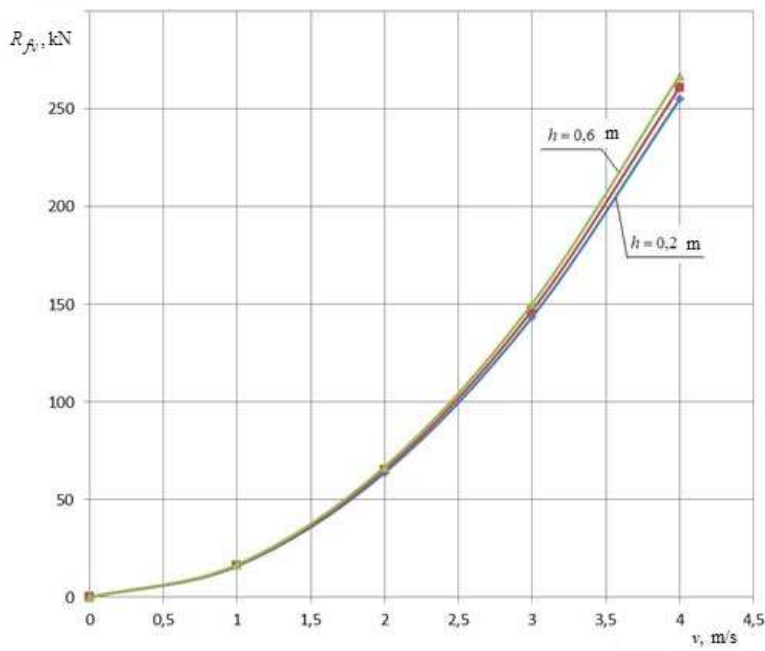

Fig. 8. Speed-dependent component of ice fragments of pure ice resistance for project 2805 icebreaker

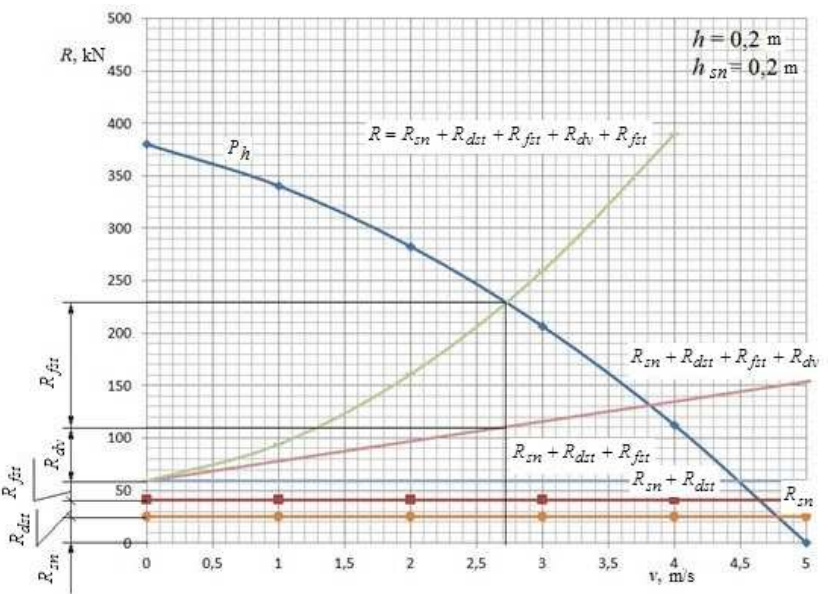

Fig. 9. Ice resistance and thrust on hook for project 2805 icebreaker, $h=0,2 \mathrm{~m}, h_{\mathrm{cH}}=0,2 \mathrm{~m}$

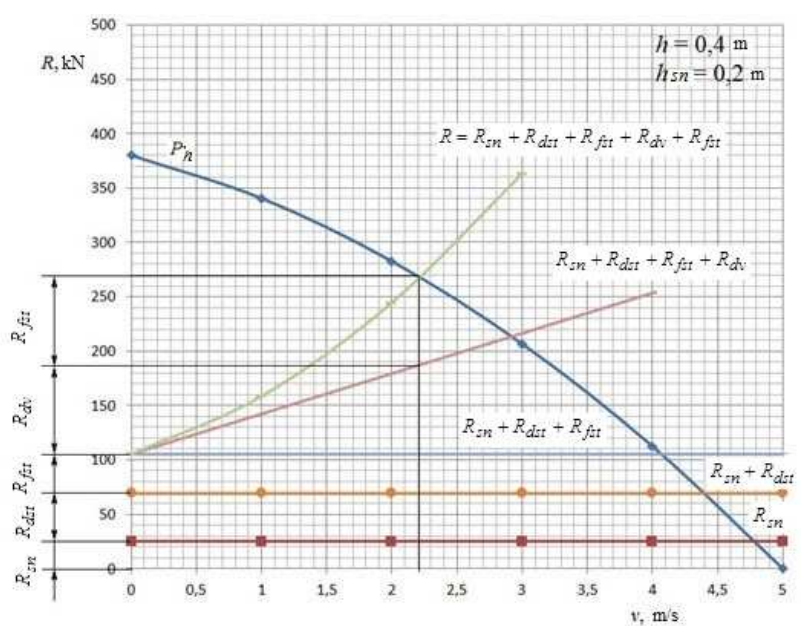

Fig. 10. Ice resistance and thrust on hook for project 2805 icebreaker, $h=0,4 \mathrm{~m}, h_{\mathrm{cH}}=0,2 \mathrm{~m}$

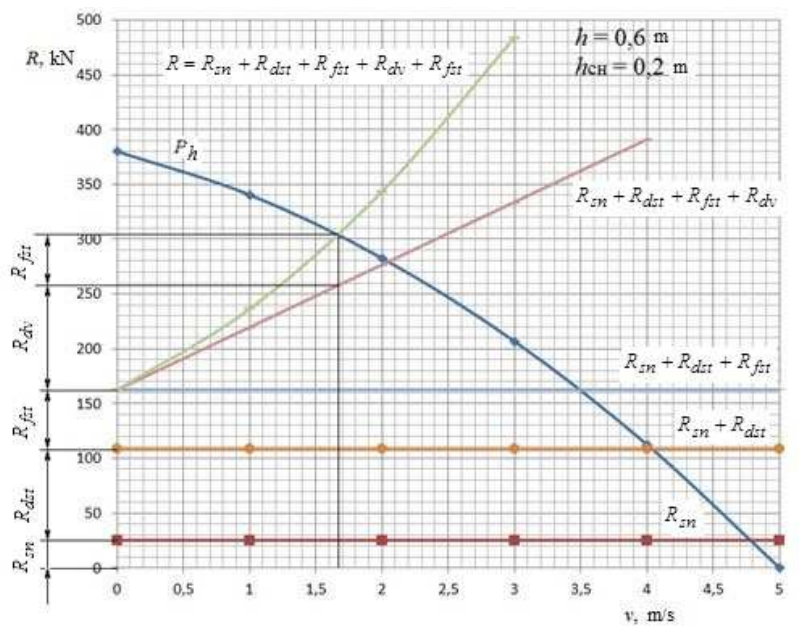

Fig. 11. Ice resistance and thrust on hook for project 2805 icebreaker, $h=0,6 \mathrm{~m}, h_{\mathrm{cH}}=0,2 \mathrm{~m}$ 


\section{References:}

[1] A.A. Dobrodeev, N.Yu. Klementyeva, K.E. Sazonov "Modern approaches to navigating large-capacity vessels in ice", Transport of the Russian Federation, No. 4 (59), pp. 29-32, 2015.

[2] B.P. Ionov, E.M. Gramuzov, Ice navigation of ships: Monograph. $\mathrm{SPb}$.: Shipbuilding, 2001, $512 \mathrm{p}$.

[3] N.V. Kalinina "Forecasts for project 2805 ice class tug propulsion while navigating in ice", Morskoy Vestnik, No. 1 (25), pp. 96-97, March 2008 .
[4] M.Yu. Sandakov, B.P. Ionov "Determination of the forces of resistance of broken ice to the movement of the vessel", Morskoy Vestnik, No. 3 (51), pp. 102-104, 2014.

[5] K.E. Sazonov "Modern problems of the propulsion of transport vessels", Shipbuilding, No. 2, pp. 23-25, 2016.

[6] K.E. Sazonov "Influence of snow cover on ice resistance of ships", Polar Mechanics, No. 3, pp. 417-42, 20167.

[7] K.E. Sazonov, A.A. Dobrodeev "Means of laying navigable canals in ice", The World of Transport, No. 1 (50), T. 12, pp. 42-49, 2014. 